\title{
STEREOLOGICAL EVIDENCES OF EPITHELIAL HYPOPLASIA OF SEMINIFEROUS TUBULES INDUCED BY MESTEROLONE IN ADULT SPRAGUE-DAWLEY RATS
}

\author{
*SHITTU LAJ, SHITTU RK OSINUBI AA, ASHIRU OA' \\ Department of Anatomy, \\ Lagos State University College of Medicine, Ikeja, Lagos, Nigeria. \\ Medical Microbiology \\ Unit, Bolomedics Laboratories, Egbeda, Lagos, Nigeria. \\ *Corresponding Author \\ E-mail:drlukemanjoseph@yahoo.com
}

\begin{abstract}
BACKGROUND: Anabolic-androgenic steroid compounds are one of the most widely abused drugs by athletes and muscle builders with the goal of improving performance/ability, appearance, or muscle mass. In addition, these steroids are widely used in the treatment of male infertility and subfertility. However, increasing concern has been shown that these compounds may not only offer unappreciable benefits to infertile and subfertile males, but might have deleterious effects on both human and animal physiology and sperm quality. There is a dearth of knowledge on the structural and quantitative changes of the testis secondary to this group of compounds.

Objective: The present study was carried out to evaluate the effects of mesterolone (proviron), an anabolic-androgenic steroid, on some of the histomorphometric and stereological parameters of the seminiferous tubules in Sprague-Dawley rat.

Materials and Methods: Two groups of 10 adult male rats were used. The treated group was given $0.06 \mathrm{mg} / \mathrm{kg}$ body weight $/ \mathrm{day}$ of mesterolone by gavage for six weeks while the control group received equal volume of $0.9 \%$ normal saline per day. Five $\mu$ m of uniformly random serial sections of the processed testicular tissues were analyzed using un-biased stereological and histomorphometric studies.

Results: The results showed that the percentage mean volume density of both the tubular lumen and epithelial height increased by $35 \%$ ( $p<$ $0.05)$ and decreased by $50 \%(p<0.05)$, respectively compared to the control. mesterolone also caused a significant decline in sperm concentration.
\end{abstract}

Conclusion: Mesterolone produces epithelial hypoplasia in the testis post continuous management.

Keywords: Testis, Mesterolone, Seminiferous tubules, Stereology.

\section{INTRODUCTION}

Increasing concern has been expressed with regards to the role of anabolic-androgenic steroid (AAS) compounds, which are one of the most widely abused drugs by athletes and muscle builders with the goal of improving performance/ability, appearance, or muscle mass. Mesterolone (1alpha-methyl-5alphaandrostan-17beta-ol-3-one) is a synthetic AAS with reported abuses in human sports (1).

Synthetic (exogenous) androgen has been used in the treatment of male infertility through its generally accepted direct stimulatory or rebound effect on the reproductive axis. This is based on the principle that the process of spermatogenesis is androgen and follicle-stimulating hormone-dependent (2). The mechanism of action of androgens is either through direct stimulatory increase in intratesticular testosterone level which enhances spermatogenesis or influence on sperm transport and maturation through its effect on epididymis, ductus deferens and seminal vesicles (3). Androgens with rebound effect (e.g. testosterone enanthate) suppress spermatogenesis and secretion of gonadotrophins (follicle-stimulating hormone and luteinizing hormone) which are usually relieved when treatment with the drugs is discontinued (3).

The abuse of AAS, especially dihydrotestosterone (DHT) by athletes is on the increase because it has been observed that DHT helps to prevent estrogenic side effects such as fat gain and water retention associated with substance abuse (4).

AAS has been shown to prevent the estrogen-dependent augmentation of the progesterone cytosol (PRc) receptors in human breast cancer cells. In addition, DHT and its metabolites demonstrate a very high degree of inhibition of estrogen in human breast cancer cells (4). Androgens are capable of inhibiting both the estrogenic induction and the ongoing stimulation of PRc receptor synthesis, but have no apparent effect upon basal concentrations of this receptor (4).

Androgenic and anabolic effects of AAS originate from activation of the androgenic receptors. The distinction between these biological effects depends on the organs and target tissues. DHT is responsible for the androgenic effect. This steroid is more potent than testosterone because of increased affinity to the androgen receptor. It is formed from conversion of testosterone by the 5á-reductase enzyme. Activity of this enzyme is important in testicles, skin, prostate, intestines, brain, bones, and adipose tissues. Therefore, androgenic effects of AAS predominate in these organs. Anabolic steroids are essentially synthetic derivatives of testosterone, modified to enhance its anabolic actions (promotion of protein synthesis and muscle growth). Anabolic effects concern organs such as muscles, bones, the heart and kidneys. These organs possess little 5áreductase activity and thus AAS compounds induce protein synthesis, muscle fibre development, erythropoiesis, and variable effects on bone growth $(5,6)$. In addition, anabolic steroids displace glucocorticoids fromglucocorticoid receptors and inhibit muscle protein catabolism, leading overall to an anabolic or muscle-building effect. Other mechanisms of direct and indirect anabolic effects include increases in the creatine phosphokinase activity in skeletal muscle, and increases in both circulating insulin-like growth factor- (IGF)1 (7) as well as up-regulation of IGF-1 receptors (8). AAS has been found to contribute to androgen action on the testis with some degree of support for residual spermatogenesis (9).

Because, mesterolone might have a beneficial effect by keeping estrogen in check, it is open to abuse by athletes. However, the conflicting outcomes of its use in the clinical settings in the treatment of male infertility have necessitated the need for this study. 


\section{MATERIALS AND METHODS}

\section{Source of drug}

The proviron (a product of Schering AG Germany/Allemagne, LOT \# WEA6WX, manufactured date (MFD): 06, 2004, expirydate (EXP): 06, 2009) used for this study was bought from a pharmaceutical shop in Agege, Lagos, Nigeria. Each oral tablet contains $25 \mathrm{mg}$ of mesterolone with 20 tablets in a bottle.

\section{Preparation of drug}

Proviron was dissolved in $100 \mathrm{ml}$ of distilled water to make up to $0.06 \mathrm{mg} / \mathrm{kg}$ body weight/day, based on the physiological calculation for a $70 \mathrm{~kg}$ man.

\section{Animal}

Twenty mature and healthy adult male Sprague-Dawley rats weighing 120 to $200 \mathrm{~g}$ were procured from the Animal House of Lagos State University, College of Medicine, Ikeja and housed in a well ventilated wire-wooden cages in the departmental Animal House. They were maintained under controlled light schedule (12 hours Light: 12 hours Dark) at room temperature $(28 \mathrm{C})$ and with constant humidity (40-50\%). The animals acclimatized for a period of 14 days before the commencement of treatment. During this period, they were fed with standard rat chows/pellets supplied by Pfizer Nigeria Ltd and water ad-libitum. Ear tag was used for the individual identification of the entire group animals.

\section{Experimental procedure}

The rats were randomly divided into two groups of ten rats each. The treated groups received $0.06 \mathrm{mg} / \mathrm{kg}$ body weight /day of proviron solution via gastric gavage (oro-gastric intubation) daily, while the control group received equal volume of $0.9 \%(\mathrm{w} / \mathrm{v})$ normal saline daily for a period of 6 weeks.

All procedures involving animals in this study conformed to the guiding principles for research involving animals as recommended by the Declaration of Helsinki and the Guiding Principles in the Care and Use of Animals (10) and approved by the Departmental Committee on ethics and research.

\section{Animal sacrifice}

The rats were anaesthetized after an overnight fasting using the procedure described in our previous study (11). Weekly weighing of the animals was carried out all through the experimental period.

\section{Organ Harvest}

The testes were initially dissected out whole via midline abdominal incision, cleared of fats and blotted dry. Their weights were measured on a sensitive digital balance while the volume was measured by water displacement using a $10 \mathrm{ml}$ measuring cylinder. Later, the sizes (length and width) were recorded by use of a sliding gauge $(\mathrm{d}=0.1)$ before eventually fixed in freshly prepared $10 \%$ formol saline solution as earlier described (11). The two testes of each rat were measured and the average value obtained for each of the parameters was regarded as one observation.

\section{Tissue processing for Light Microscopy}

Serial paraffin sections of $5 \mu \mathrm{m}$ were obtained from fixed processed testicular tissue blocks and stained with Haematoxylin and Eosin (H \& E) stains as prepared and previously described in our earlier studies $(9,11)$.

\section{Morphometric parameters}

The following morphometric parameters: testicular volume and weight; diameter; and cross-sectional area of the seminiferous tubules, were determined.

The diameter (D) of seminiferous tubules with profiles that were round or nearly round for each animal was estimated. A mean, D, was taken as the average of two diameters, D1 and D2 (D1 is the short axis while, D2 is the long axis). D1 and D2 were considered only when ratio of D1: D2 or D1/D2 $>0.85$ (Form factor).

The cross-sectional areas $\left(\mathrm{A}_{c}\right)$ of the seminiferous tubules was determined from the formula

$\mathrm{A}_{c}=ð \mathrm{D} / 4$, (where $\delta$ is equivalent to 3.142 and $\mathrm{D}=$ the mean diameter of the seminiferous tubules).

\section{Determination of stereological parameters}

Serial transverse sections of $5 \mu \mathrm{m}$ of the $\mathrm{H} \&$ E-stained specimens prepared were subjected to un-biased stereological techniques modified from previous report (12). Each image of the seminiferous tubules at a magnification of $400 \mathrm{x}$ was projected and drawn on a 16-point grid, completely counted in 6 different fields to make a total of 96 point-test grid for each of the 5 sections/rat from each group. Manual point/intercept counting methods consist of a counting grid made up of a series of crosses in a regular and uniform square array. The density of crosses was such that one cross represented an area of $4 \mathrm{~cm}^{2}$ on the counting grid. The total number of crosses (circled or otherwise) falling on each structure of interest was counted for each section and summated. Using this procedure, the volume density of the stroma, epithelia lining and tubular lumen of seminal vesicles were estimated as previously described by Weibel and Gomez (13). The percentage volume density was determined by multiplying the volume density by 100 .

\section{Statistical analysis}

Data were expressed in Mean $\pm \mathrm{SD}$ (standard deviation). All the data were inputted into, and analyzed by SPSS (Statistical Package for Social Sciences). Comparison between groups was done using the student's $t$-test and non-parametric Mann-Whitney $\mathrm{U}$ test. Statistical significance was considered at $p<0.05$.

\section{RESULTS}

Evidence of significant $(p<0.05)$ weight gain was observed in all the animals. Both the raw testicular weight and relative testicular weight decreased significantly $(p<0.05)$ in the provirontreated group as compared to the control (table 1).

The mean caudal epididymal sperm concentration of the control group was significantly $(p<0.05)$ higher than the provirontreated group $\left(80 \pm 17.6 \mathrm{vs} .58 \pm 24.5 \times 10^{\circ}\right)($ table 1$)$.

The percentage mean volume density of the tubular lumen increased by $35 \%$, while that of the epithelial height deceased by $50 \%(p<0.05)$ in the proviron-treated rats when compared to the control (table 2). The mean diameter of the seminiferous tubules of proviron-treated group $(305.3 \pm 4.9 \mu \mathrm{m})$ was significantly $(p<0.05)$ different from that of the control $(295.5 \pm 5.0 \mu \mathrm{m})$ (table 2). 
Table 1: Effects of proviron (mesterolone) on sperm concentration, testicular and body weights of Sprague-Dawley rats

\begin{tabular}{llllll}
\hline $\begin{array}{l}\text { Treatment } \\
\text { Group }(\boldsymbol{n}=\mathbf{1 0})\end{array}$ & $\begin{array}{l}\text { Pre-experimental } \\
\text { body weight }(\mathbf{g})\end{array}$ & $\begin{array}{l}\text { Final body } \\
\text { weight }(\mathbf{g})\end{array}$ & $\begin{array}{l}\text { Testicular } \\
\text { weight }(\mathbf{g})\end{array}$ & $\begin{array}{l}\text { Testicular body } \\
\text { weight }(\mathbf{w t} / \mathbf{1 0 0 g} \\
\text { body weight) }\end{array}$ & $\begin{array}{l}\text { Sperm } \\
\text { count (x10*) }\end{array}$ \\
\hline Control & $127.3 \pm 6.40$ & $184.4 \pm 12.6$ & $1.24 \pm 0.01$ & $0.67 \pm 0.01$ & $80 \pm 17.6$ \\
Proviron & $159.4 \pm 5.16$ & $185.2 \pm 12.8$ & $0.89 \pm 0.09^{*}$ & $0.55 \pm 0.01^{*}$ & $58 \pm 24.5^{*}$ \\
\hline
\end{tabular}

Values are mean \pm SD

*: Significantly different from the control group at $p<0.05$

Table 2: Effects of proviron (mesterolone) on volume fraction of testicular tissue profile and diameter of seminiferous tubule of Sprague-Dawley rats

\begin{tabular}{lllll}
\hline Treatment Group & Interstitium & Surface Epithelia & Tubular Lumen & $\begin{array}{l}\text { Seminiferous } \\
\text { Tubular Diameter }(\boldsymbol{\mu m})\end{array}$ \\
\hline Control & $0.14 \pm 0.06$ & $0.82 \pm 0.06$ & $0.04 \pm 0.01$ & $305.3 \pm 4.9$ \\
Proviron & $0.31 \pm 0.06^{*}$ & $0.4 \pm 0.08^{*}$ & $0.19 \pm 0.04^{*}$ & $295.5 \pm 5.0^{*}$ \\
\hline
\end{tabular}

Values are mean $\pm \mathrm{SEM} ; n=10$ in each group.

*: Significantly different from the control group at $<0.05$.

\section{DISCUSSION}

We now know that combination of a well characterized animal model with stereological techniques always allow for proper quantitative study of any hormonal impact on male reproductive system (14). Application of stereological and morphometric techniques as new approaches in modern medicine and biomedical sciences/researches are on the increase in recent years (15).

This present study had used matured adult male rats because morphometric study by light microscopy is best performed when the organ has reasonably developed to a sizable dimension (15). In addition, rat appears to be a suitable animal model for studying the roles of the androgenic hormones within the male reproductive system in that it operates on a two-way androgen model of sexual differentiation (DHT and testosterone), unlike, in mouse model which is dependent on testosterone action alone for the differentiation of the male urogenital tract (16).

In this study, we have utilized stereological technique and histomorphometric analysis to compare the effects of oral proviron intake with normal saline on the testis of adult male Sprague-Dawley rats. Proviron was found to reduce the testicular weight as compared to control. This is contrary to the effect of proviron which is thought to enhance weight gain (4). These differential changes in weight of testes were well correlated with the seminiferous tubular profile of the testes for each group of animals.

Since, proviron is a known androgen that binds to the androgen receptor in the testis, one expects that it would stimulate spermatogenesis because DHT strongly binds to the receptor than testosterone and also have more appreciable effect on it. This is however, not our experience in this study, as proviron-treated rats had lower sperm concentration than the controls. The reason for this is not clear. The marginal value recorded for the mean volume fraction of the surface epithelium of the seminiferous tubules of the treated group might be an indication of some residual spermatogenesis seen in the testis.

Studies have shown that sections of tissues are usually compressed by $83 \%$ of their original dimension, thereby necessitating the need of a correction factor. However, volume densities are not affected by this compression (12) and hence appeared more suitable for the present study.

The increase of $35 \%$ in percentage mean volume density of the seminiferous tubular lumen and 50\% decrease in epithelial height showed that proviron has reduced epithelial height and activity, thus it is not surprising that spermatogenic activity and sperm output were reduced by $50 \%$ compared to the control in this present study.

Degenerative features such as luminal dilatation (up to $35 \%$ ) and reduction in the epithelial height amongst others are factors that probably culminated in testicular atrophy in the provirontreated rats. These findings are in consonance with observations from some earlier work $(19,20)$, but at variance with a study that found that 17 á-propylmesterolone, a synthetic 5 alphareduced steroid had no influence on testes weights (21)

There is no doubt that a complex hormonal interplay exists at the level of the hypothalamic- testicular axis, which may partly be responsible for our findings. Further studies are, however, necessary to elucidate the exact mechanism of proviron-induced seminiferous atrophy.

\section{CONCLUSION}

Proviron induces atrophy of the seminiferous tubules of adult Sprague-Dawley rats and disrupts spermatogenesis. The role of this steroid in the management of male infertility will need to be reviewed based on the results of present study. In fact, proviron could probably have a role to play as hormonal contraceptive in the light of present findings.

\section{REFERENCES}

1. Ho EN, Leung DK, Leung GN, Wan TS, Wong HN, Xu X, Yeung JH. Metabolic studies of mesterolone in horses. Anal Chim Acta, 2007; 596(1): 149-155.

2. Abel MH, Baker PJ, Charlton HM, Monteiro A, Verhoeven G, De Gendt K, Guillou F, O'Shaughnessy PJ. Spermatogenesis 
and Sertoli Cell Activity in Mice Lacking Sertoli Cell Receptors for Follicle-Stimulating Hormone and Androgen. Endocrinology, 2008; 149 (7): 3279-3285.

3. Vandekerckhove P, Lilford R, Vail A, Huges E. Androgen versus placebo or no treatment for idiopathic Oligo/asthenospermia, Cochrane database System Rev, 2000; (2): CD000150.

4. Roberts A, Clapp B. Designing an Anabolic Steroid Cycle. Anabolic Steroids - The Ultimate Research Guide. Amazon, 2006.

5. Handelsman DJ. Androgen action and pharmacologic uses. In: DeGroot LJ, Jameson JL, eds. Endocrinology. Philadelphia: WB Saunders, 2000, 2232-2242.

6. Saudan C, Baume N, Robinson N, Avois L, Mangin P, Saugy M. Testosterone and doping control. Br J Sports Med, 2006; 40(Suppl 1): 21-24.

7. Arnold AM, Peralta JM, Thonney ML. Ontogeny of growth hormone, insulin-like growth factor-I, estradiol and cortisol in the growing lamb: effect of testosterone. J Endocrinol, 1996; 150(3): 391-399.

8. Urban RJ, Bodenburg YH, Gilkison C, Foxworth J, Coggan AR, Wolfe RR, Ferrando AA. Testosterone administration to elderly men increases skeletal muscle strength and protein synthesis. Am J Physiol, 1995; 269: E820-E826.

9. Shittu LAJ. The effect of the aqueous crude leaves extract of Sesamum radiatum compared to Mesterolone (proviron) on the adult male Sprague Dawley rats testis and epididymis. Lagos: Lagos State University, MSc. Dissertation, August, 2006.

10. American Physiological Society. .Guiding principles for research involving animals and human beings. Am J Physiol Regul Integr Comp Physiol, 2002, 283, R281-R283.

11. Shittu LAJ, Bankole MA, Oguntola JA, Ajala O, Shittu RK, Ogundipe OA, et al. Sesame Leaves Intake Improve and Increase Epididymal Spermatocytes Resreve In Adult Male Sprague Dawley Rat. Scientific Research and Essays, 2007; 2 (8): 319-324.

12. Mouton PR. Principles and Practices of Unbiased Stereology-Introduction for Bioscientists. Baltimore,
Maryland: The John Hopkins University Press. 2002; 1214.

13. Weibel ER, Gomez DM. A principle for counting tissue structures on random sections. J Appl Physiol, 1962; 17: 343-348.

14. McLachlan RI, Wreford NG, de Kretser DM, Robertson DM. The effects of recombinant follicle-stimulating hormone on the restoration of spermatogenesis in the gonadotropin-releasing hormone-immunized adult rat. Endocrinology, 1995; 136: 4035-4043.

15. Mukerjee B, Rajan T. Morphometric Study of Seminal Vesicles of Rat in Normal Health and Stress Conditions. $J$ Anat Soc, 2006; 55 (1): 31-36.

16. George FW, Johnson L, Wilson JD. The effect of a 5 alphareductase inhibitor on androgen physiology in the immature male rat. Endocrinology, 1989; 125: 2434-2438.

17. Blouin A, Boender RP, Weibel ER. Distribution of organelles and membranes between hepatocytes and non hepatocytesin the rat liver parenchyma. J Cell Biol, 1977; 72: 441-455.

18. Hess RA, Gist DH, Bunick D, Lubahn DB, Farrell A, Bahr J, et al. Estrogen receptor (á and â) expression in the excurrent ducts of the adult male rat reproductive tract. JAndrol, 1997; 18: 602-611.

19. Oliveira, CA, Carnes, K, Franca, LR, Hess, RA. Infertility and testicular atrophy in the antiestrogen-treated adult male rat. Biol Reprod, 2001; 65:913-920.

20. Luderschmidt C, Eiermann W, Jawny J, Bidlingmaier F, Ring J. 17 alpha-Propylmesterolone (SH 434): an antiandrogenic sebosuppressive substance not influencing circulating testosterone concentrations. Experimental studies in Syrian hamsters. Naunyn Schmiedebergs Arch Pharmacol, 1984; 328(2): 214-218.

\section{ACKNOWLEDGEMENT}

The authors wish to thank the Department of Anatomy, Lagos State University College of Medicine for their support towards this study and the secretariat assistance of Mrs. Dorcas Adebayo is hereby greatly appreciated. 